\title{
Dinâmica espacial da hotelaria de luxo na metrópole de Sáo Paulo: da expansão à crise e o estágio atual
}

Carlos Costa da Silva. Universidade Federal de São Carlos, Sorocaba, Brasil.

RESUMO | A metrópole paulista vem passando nas últimas duas décadas por grandes transformações em sua forma, em suas funçôes e nos processos que balizam a sua reprodução. Estudar a hotelaria nos auxilia a enxergar o movimento de transformação da metrópole a partir da análise dos sujeitos envolvidos no processo de reprodução do capital imobiliário em conformidade com o financeiro na produção de novos edifícios e no reforço das novas áreas de centralidade em São Paulo.

PALAVRAS-CHAVE | concentração espacial, urbanização, serviços urbanos.

ABstract | São Paulo has experienced over the past two decades great changes in its form, functions and reproductions process. Studying the hospitality sector helps us to see the movement of the metropolis transformation from the vantage point of the subjects involved in the reproduction of real state capital along with financial capital in accordance with the financial production of new buildings and in strengthening of centrality's new areas in São Paulo.

KEYWORDS | spatial concentration, urbanization, urban services.

Recibido el 15 de mayo de 2013, aprobado el 17 de septiembre de 2013

E-mail: ricougo@ufscar.br 


\section{Introdução}

O objetivo deste artigo é analisar o papel que os empreendimentos hoteleiros desempenharam na história recente de São Paulo, destacando os principais fatores que interferiram nas mudanças no padrão de localização, nos serviços e na gestáo imobiliária-administrativa do setor. Nossas análises se baseiam nos empreendimentos hoteleiros considerados de luxo ou de alto padrão ou com classificação 5 estrelas. A pergunta que baliza nossas reflexóes está baseada na hipótese de que a hotelaria acompanha o processo de construção de novas áreas de centralidade em São Paulo, participando como um setor que reforça e facilita a concentração de capitais e pessoas a partir da consolidação de uma determinada área como centro de negócios e de turismo. Quais as relaçôes existentes entre a consolidação de São Paulo como destino de negócios e de turismo com o desenvolvimento da hotelaria? De que maneira a hotelaria participa do processo de reprodução do espaço da metrópole, interferindo na produção e consolidação de novas áreas de centralidade? Qual foi a resposta dada pelo setor hoteleiro paulistano tendo em vista as novas configuraçôes socioespaciais do sistema capitalista de produção?

\section{A participaçáo da hotelaria na produçáo do espaço da metrópole paulista}

No século XIX podemos afirmar que é com o incremento na circulação de bens, serviços, pessoas e capitais, impulsionados pela produçáo cafeeira, que permitiu o surgimento dos primeiros hotéis na cidade. $\mathrm{O}$ aumento no fluxo de viajantes e visitantes que passavam por São Paulo devido ao início das atividades comerciais advindas da produção cafeeira no interior e seu consequente transporte até o Porto de Santos cruzando a cidade de São Paulo favoreceram o aparecimento dos primeiros meios de hospedagem organizados na cidade. Entre 1880 e 1930, São Paulo passa de uma cidade com aproximadamente 250.000 habitantes para uma metrópole com mais de 2 milhóes de pessoas. A riqueza gerada pelos excedentes da produção cafeeira lhe permitiram ampliar a oferta de novos serviços ao mesmo tempo que a demanda cresce exponencialmente, como demonstra Carlos e Pintaudi (1995, p. 23).

Até a década de 1930, em São Paulo, a hotelaria se consolidou com diversas unidades de variados tamanhos e padróes de serviços presentes, basicamente, no centro na cidade e ao redor das estaçóes ferroviárias, além de algumas pensóes e hospedarias em bairros industriais ou estritamente residenciais. O hotel que marca esse período é o Grande Hotel Esplanada localizado ao lado do edifício do Teatro Municipal no Vale do Anhangabaú.

Com a expansão efetiva da industrialização na cidade de São Paulo e em sua Regiâo Metropolitana entre 1930 e 1970, a hotelaria paulistana tomou outros contornos. As técnicas da construção civil se especializaram ao ponto que hotel virou sinônimo de edifício com pelo menos seis pavimentos, grande quantidade de janelas, esquadriais, portais, beiradas, sacadas, jardins e retoques especiais no trato do desenho arquitetônico no seu projeto de construção e decoração. $\mathrm{O}$ marco deste período em São Paulo foi o Othon Palace Hotel construído na década de 1950, 
localizado no Viaduto do Chá, ao lado da sede das empresas Matarazzo. Esse hotel revolucionou os padrôes de construção até então estabelecidos por ter muitos artigos, móveis e serviços de luxo a disposição de seus hóspedes. Este período de quarenta anos correspondeu à consolidação da cidade de São Paulo como capital industrial do país e motor da economia nacional. Como centro econômico nacional, a cidade desempenhou um papel aglutinador no fluxo de pessoas e bens para seus limites, necessitando expandir seu parque hoteleiro para além dos tradicionais meios de hospedagens localizados na área central em torno dos distritos da Sé e da República.

Ao final da década de 1960, a tendência da expansão dos negócios em São Paulo se consolidou, surgindo a vertente do Rio Tietê em direção ao espigáo da Avenida Paulista no interflúvio com o Rio Pinheiros como área primaz para os investimentos em hotéis na cidade de São Paulo. A região do centro histórico (distritos Sé e República) perdeu lugar como referência para as sedes empresariais e negócios privados, para a regiáo da Avenida Paulista. Ainda que o centro histórico ganhasse fluidez ao se inaugurarem as primeiras estaçóes da rede metroviária, o que permaneceu no centro foram os serviços públicos e o comércio popular, migrando, através do eixo formado pelas Avenidas Angélica, Rua Augusta e da Consolação, o comércio das elites, os escritórios e os serviços mais especializados, concentrando-se nos bairros da Bela Vista, Cerqueira César e Jardins.

É importante citar neste período a inauguração do Shopping Center Iguatemi em 1966 no bairro de Pinheiros nas várzeas do rio de mesmo nome. Seus efeitos espaciais contidos na expressão da centralidade urbana começaram a ser vistos ao longo de toda a década de 1970, quando a vertente sudoeste da Rua Augusta e sua continuação através da Rua Colômbia e Avenida Europa, além das Alamedas perpendiculares como a Lorena e a Rua Oscar Freire, começaram a receber lojas elegantes para as elites que residiam nas proximidades, modificando por completo a estrutura do comércio de luxo de São Paulo. Ao mesmo tempo, a inauguração do MASP na década de 1950, trouxe nova circulação de pessoas para a Avenida Paulista que passou a receber, além de visitantes a trabalho, outros que passaram a buscar a Avenida por motivos de lazer e cultura, em busca da arte em exposição no museu.

Neste período, temos que considerar três grandes marcos da hotelaria paulistana: o primeiro é o Hilton Ipiranga, inaugurado em 1971, o segundo é o Ceasar Park localizado na Rua Augusta e inaugurado em 1976 e o terceiro é o Maksoud Plaza, localizado na Alameda Campinas, inaugurado em 1979.

Deve-se analisar a inauguração desses três hotéis pela relação tempo e espaço. Em oito anos, o caminho de localização dos hotéis de luxo seguiu, ou melhor, "subiu", em direção ao espigão da Avenida Paulista. Ainda em 1971, o Hilton, primeiro hotel de rede internacional a funcionar no Brasil, o que mostra a importância nacional em nível mundial da cidade, abriu sua unidade na área central (Avenida Ipiranga esquina com Avenida São Luís e Rua da Consolação), região que unida aos hotéis da Rua Avanhandava, Vieira de Carvalho e Frei Caneca formavam o principal eixo hoteleiro de São Paulo. É aí também que funcionavam o Bourbon São Paulo, o Hotel Jaraguá e o Hotel Ca'd'oro, importantes referenciais de hospedagem de alto padrão para a cidade. Como era facilmente alcançado por importantes vias de circulação rápida, este hotel permaneceu como opção de hospedagem de luxo para 
os viajantes. Em 1976, o Ceasar Park abriu sua unidade de luxo já bem próxima a Avenida Paulista, lugar de concentração dos viajantes a negócios nesta época. Com a inauguração do Maksoud Plaza em 1979 com toda a infraestrutura que este hotel passou a oferecer, além da beleza arquitetônica do prédio, a Avenida Paulista tornou-se o lugar de concentração da hotelaria de alto padrão da metrópole. $\mathrm{Ou}$ seja, a regiáo da Avenida Paulista deixou de ser concorrente com a área central para hospedagem de luxo, pois passou a ser a única opção.

A década de 1970 transformou o perfil da hotelaria paulistana, pois introduziu no mercado local, as redes internacionais ${ }^{1}$. Ou seja, não foi apenas no plano do comércio ou da indústria que se intensificou com a entrada de empresas estrangeiras ao país. Nos serviços, caso da hotelaria, isso também aconteceu e de maneira rápida como nos outros setores, revelando o rápido processo de internacionalização que aconteceu na economia brasileira.

Os dez anos seguintes foram de grande retração na economia brasileira em relação ao crescimento do PIB, ainda que alguns setores continuassem crescendo bastante e rapidamente, caso do comércio. O setor hoteleiro foi um dos mais atingidos pela recessão, que não cresceu em um número significativo de unidades como nos anos anteriores. Em São Paulo, somente o Crowne Plaza (1986) e o Sheraton Mofarrej (1986) abriram suas portas na Rua Frei Caneca e Alameda Santos respectivamente, todos sendo administrados por redes internacionais de grande porte. Todos os demais hotéis que se inauguraram no período, trabalhavam com serviços voltados para hóspedes que pagavam diárias mais baratas. Ou seja, a década de 1980 se caracterizou para a hotelaria como um período de falta de investimentos em novas unidades. No entanto, com a estabilizaçáo da economia nacional a partir de 1994 e a consequente abertura econômica efetivada com a nova configuração política nacional e internacional possibilitada por relaçóes globalizadas no que diz respeito aos fluxos econômicos, o setor hoteleiro, aliado ao crescimento dos fluxos de viajantes advindos do aumento sustentado das viagens turísticas em ordem mundial, vai se apresentar como possibilidade econômica para investir em novas unidades, a partir da construção de novos hotéis.

Assim, o período entre o final da década de 1980 e início da década de 1990, além de ser pontuado por uma grande transformação política-fim do regime militar, abertura política, eleiçóes diretas e democráticas, diversos planos econômicos que tentavam estabilizar a economia nacional-foi marcado por uma reviravolta nos padróes de reproduçáo do capitalismo em nível internacional. Ou seja, passou a ocorrer transferência dos investimentos advindos do capital industrial para o capital financeiro em circulação pelo mundo, a partir do ganho de importância das bolsas de valores e do mercado de açóes, fruto da reconversão nos padróes de produçáo baseados no fordismo para padróes mais flexíveis na produção industrial, conforme Harvey (1992).

A expansão da economia industrial encontrou seus limites no Brasil durante a década de 1970 em virtude das mudanças acontecidas na economia mundial na

1 A rede francesa Accor, as norte-americanas Sheraton, Intercontinental, Carson e outras, também abriram unidades em São Paulo e pelo Brasil nestas décadas. 
Europa, América do Norte e Extremo Oriente Asiático. As condições que garantiam a reprodução do capital de base industrial se viram em crise no Brasil ao final do período militar e início da década de 1990. O dinheiro em circulação pelo mundo encontrou novas maneiras para se materializar, buscando novos territórios e setores para investir. No plano brasileiro, o que se presenciou ao longo das décadas de 1970 e 1980 foi a desconcentração da indústria paulista para seu entorno imediato $(150 \mathrm{~km}$ ao redor da capital do Estado), produzindo no plano espacial, a constituiçáo de uma macro-metrópole nos termos empunhados por Lencione (1997).

Desde 1970 até meados da década de 1990, o setor hoteleiro sofreu grandes transformaçóes advindas do processo de reestruturaçáo econômica internacional no qual pode ser traduzido pela crescente entrada de empresas multinacionais no país que passaram a investir na hotelaria nacional com novas unidades, sobretudo hotéis de luxo. Este fato é explicado pelo baixo ritmo de crescimento econômico nacional durante a década de 1980, onde somente o setor de luxo conseguiu se manter em expansão, pois foi um dos menos afetados pela recessão.

\section{A hotelaria e sua relaçáo com o mercado imobiliário e financeiro}

A partir de meados dos anos 1990, podemos considerar que uma nova fase se inaugura para a hotelaria paulistana. Se a década anterior foi de extrema retração no processo de expansão de novos hotéis, a partir de 1995, houve uma modificação. Aliada a estabilização da economia e a política nacional de privatizaçóes por meio de investimentos estrangeiros diretos no país, o setor hoteleiro revelou-se como uma grande oportunidade para novos investimentos nos mais diversos tipos de hotéis, sobretudo os hotéis de padrão intermediário, superior e de luxo. Conforme Spolon (2006, p. 22), quando analisou os discursos encontrados no mercado hoteleiro durante a década de 1990, as razóes apontadas para o incremento de novos hotéis no parque hoteleiro paulistano são as seguintes:

- a estrutura hoteleira existente no início da década de 1990 era inadequada, sendo necessário um considerável investimento para renová-lo, em especial por não ter havido, nas décadas anteriores, investimentos significativos na construção de hotéis;

- eram elevados os valores cobrados pelos hotéis paulistanos, em especial pelos mais luxuosos, o que sinalizava a importância de o parque hoteleiro local dispor de opçôes mais baratas de hospedagem, com bom nível de conforto;

- vinham sendo registradas no município taxas médias anuais de ocupação de cerca de $70 \%$, bem próximas do limite imposto pela sazonalidade regular do turismo de negócios, o que seria um indício de existência de demanda nãoatendida por unidades hoteleira e;

- era preciso renovar a força de trabalho, adotando critérios mais profissionalizantes de operação e investindo no desenvolvimento da mão-de-obra local.

A partir do estudo de Spolon (2006) pode-se perceber que o início da década de 1990 trazia uma nova etapa para o desenvolvimento do parque hoteleiro paulistano. O setor começava a dar indícios de saturação pela alta taxa de ocupação e 
pela demanda por hospedagens mais baratas, porém confortáveis, o que sinalizava a possibilidade de desenvolver novos produtos, já vinculados a um perfil de mão de obra mais qualificada e treinada para servir, conforme os novos ditames da gestão administrativa surgidos ao longo da década de $1990^{2}$. Assim, o setor passou a criar condiçóes favoráveis para seu crescimento rápido aproveitando-se do momento econômico de estabilidade e pela oferta de capital disponível, sobretudo no setor imobiliário, para investir na construção civil com apoio de políticas estatais, a partir do BNDEs (Banco Nacional de Desenvolvimento), em uniáo com a expansão das operaçóes das empresas já instaladas no Brasil como Hilton, Ceasar, Othon, Accor, Sheraton, Bourbon e outras, além de inúmeras empresas que pretendiam investir diretamente na gestão hoteleira em novas unidades na cidade de São Paulo.

Do ponto de vista do mercado hoteleiro havia demanda reprimida por novos hotéis, principalmente de padrão intermediário e superior; eram praticados altos preços nas unidades em funcionamento; havia necessidade de renovação e treinamento da mão de obra; vontade de expandir os negócios das empresas aqui já instaladas além de disposição para a entrada de novas empresas, sobretudo estrangeiras.

Do ponto de vista econômico, a década de 1990 revelou um novo momento para o Brasil com a estabilização da moeda, das taxas de inflação e de crescimento do PIB de forma lenta, porém contínua, num processo de transformação da estrutura produtiva nacional com as privatizaçóes em diversos setores, apontando para a constituição de uma política econômica neoliberal, deixando a cargo dos agentes hegemônicos internacionais a construção do caminho a ser seguido pelo país nos próximos anos. Além disso, a crescente disponibilidade de capitais advindos de outros setores, como telecomunicaçôes, informática, finanças e indústria de forte base tecnológica, apontavam para uma diversificação dos investimentos das grandes empresas que passaram a trabalhar com ramos diferenciados a partir de novos arranjos e contratos, conforme as análises de Chesnais (1995) indicaram. Esse autor trabalha com o processo de mundialização do capital e da força das grandes empresas multinacionais no rearranjo dos territórios nacionais, onde o capital disponível para investimento em novos setores passou a se concentrar no mercado financeiro e nas operaçóes internacionais em rede a partir da compra e venda de açóes em bolsas de valores, introduzindo alta volatilidade no capital disponível em circulação para investimentos nos países e nos setores que mais rapidamente pudessem reproduzir de forma ampliada o capital investido inicialmente.

Do ponto de vista da localidade, esse momento é caracterizado pela transformação efetiva do espaço metropolitano a partir da expansão da centralidade dos negócios na cidade de São Paulo. Se afirmamos que a Avenida Paulista se tornou

2 Trabalhadores com nível superior formados em cursos de turismo e hotelaria, tendo domínio da língua inglesa, bom manuseio de recursos de informática, boa aparência pessoal e jovens com espírito empreendedor e dedicados ao crescimento da empresa de trabalho. Esse perfil de profissional foi desenvolvido pelas empresas do setor e largamente incorporado pela sociedade, tanto é que é durante a década de 1990 que houve o boom da abertura de cursos de graduaçáo em turismo, apoiados pelo Ministério da Educação que aprovava o credenciamento de Centros Universitários que passassem a oferecer vagas nesta área, já que o mercado necessitava de profissionais capacitados nesta área para se expandir. 
o centro efetivo da economia globalizada paulistana na década de 1970 e que uma estrutura hoteleira se firmou nas suas adjacências nos anos posteriores, é no decorrer dos anos noventa e primeira década do século Xxi que houve a incorporação de novas áreas da cidade requeridas pelo processo de expansão dos negócios em São Paulo. As Avenidas Faria Lima e Luís Carlos Berrini se desenvolveram como novas oportunidades para o crescimento efetivo da indústria hoteleira, já que passaram a ser consideradas como novas áreas de centralidade com efetivo investimento em infraestrutura e incorporação imobiliária por meio da expansão do número de edifícios voltados para o mercado de escritórios e sedes empresariais, ou seja, para uso corporativo.

Carlos (2004b) analisa as transformaçóes socioespaciais advindas da passagem do capital industrial para o capital financeiro no comando do processo de reprodução do espaço no plano metropolitano, a partir da emergência de reestruturaçóes na economia capitalista atual e os produtos socioespaciais produzidos por esta dinâmica e afirma que tais transformaçóes têm requerido novos ambientes para a reprodução do capital financeiro e imobiliário nas grandes cidades. Assim, surgem novas partes nas metrópoles produzidas pela força do capital hegemônico, que auxilia na indução de reformas urbanas.

Devido às novas articulaçóes que estão ocorrendo na circulação do capital ao redor do mundo em diferentes esferas (industrial, comercial, financeira), há uma sinalização para a extensão do capitalismo em um plano cada vez mais amplo, pois este necessita possibilitar a integração de novos espaços ao sistema mundial para que continue a expandir-se. Esse movimento contempla a desestruturação e deterioração de alguns espaços, que passam a perder suas vantagens competitivas para outros, e estes, ganham importância e centralidade atraindo novos investimentos e a relocalizaçáo dos antigos. Desta forma, concordamos com Harvey (2005, p. 83), quando afirma que "o capital excedente de um lugar pode encontrar emprego noutro lugar em que as oportunidades de lucro ainda não foram exauridas".

Harvey (2005) aponta que modificaçóes nos ambientes das grandes cidades do mundo revelam adaptaçóes espaciais para oferecer melhores vantagens em termos de localização para os agentes econômicos hegemônicos. Assim, no plano urbano, dinâmicas territoriais vão se processar com o intuito de promover o melhor ambiente para a realização dos negócios contemporâneos, sobretudo com a construção de obras de sistemas infra estruturais que os apoiem, propiciando maior fluidez ao espaço.

Nobre (1999), Silva (2001), Ferreira (2003), Carlos (2004a, 2004b e 2005), Tourinho (2005) e Fix (2007) são alguns autores que analisam a questão do surgimento de novas áreas na cidade vinculadas ao capital hegemônico e a problemática da produção do espaço geográfica. Discutem a participação da região da Marginal do Rio Pinheiros, extensão da Avenida Faria Lima, Avenida Juscelino Kubitscheck, Avenida Eng. Luis Carlos Berrini e todo o vetor sudoeste (Rolnik, 2001) como uma nova área da metrópole que passou a concentrar empresas de serviços e finanças de origem nacional e estrangeira, gerando um fluxo intenso de circulação de pessoas e mercadorias além de atrair outras firmas de diferentes ramos, que possibilitou a formação de um novo centro de negócios para a cidade.

Essas áreas localizadas nas próximas destas avenidas configuraram-se na última década do século xx, como um dos novos redutos do chamado terciário superior 
em São Paulo, definindo um polígono compreendendo partes dos distritos de Itaim Bibi, Moema, Santo Amaro e Pinheiros. Essa área de aglomeração do setor terciário está servida pelo estoque de terras ainda existentes nos bairros Chácara Santo Antônio, Real Parque e Morumbi, conforme Tourinho (2005, p. 277).

Vale lembrar que, sem a atuação do poder público, essas transformaçóes não poderiam ocorrer de forma táo rápida e constante. O Estado passa a ser o mediador dessas mudanças, modificando as leis de zoneamento e desapropriando áreas da cidade, que deixam de ser apenas residenciais e passam a ser comerciais.

Um clima de negócios atraente constitui um polo de atração de fluxos de capital, razão pela qual os Estados se desdobram para aumentar seus próprios poderes mediante a criação de paraísos para o investimento de capital. Assim agindo, usam como sempre, os poderes do monopólio inerentes ao espaço para tentar oferecer privilégios monopolistas a quem quer que possa deles tirar proveito (Harvey, 2005, p. 92).

Trata-se de um momento de transferência de capital hegemônico, passando do industrial para o financeiro, baseando-se este em novas atividades ligadas aos serviços modernos, ao lazer, às atividades de comunicação e produção da informação.

Este processo de transformação redefine a fluidez, estendendo a centralidade dentro da metrópole, articulando pólos diferenciados, com uma nova concentração das atividades de comércio, serviços e de lazer, fruto da mobilidade do capital que migra de um setor a outro da economia em função das necessidades da reprodução, redefinindo a produçáo do espaço metropolitano (Carlos, 2005, p. 30).

Essa área da cidade de São Paulo pode ser considerada como um símbolo entre todas aquelas que passaram por processos de rápida e forte incorporação imobiliária que levaram à construção de áreas destinadas à realização de negócios corporativos em diferentes cidades brasileiras. A concretização e sucesso, do ponto de vista do empresariado, da Operação Urbana Faria Lima, abriu novas possibilidades de investimento em imóveis corporativos nesta região da cidade conforme Carlos (2001).

$\mathrm{Na}$ década de 1990, era a região que apresentava as "melhores" condiçôes para o desenvolvimento de um novo centro corporativo para a cidade latino-americana que mais crescia em importância em nível internacional e que acabou atraindo para seu território, cada vez mais, novas sedes empresariais, novas atividades de gestão, representação e coordenação de investimentos do mercado financeiro e de novos setores vinculados à produção e difusão da informação como publicidade e marketing digital, por exemplo.

Menos densa e com mais disponibilidade de terrenos para construir edifícios, já elaborados com novos recursos tecnológicos e que não eram encontrados na regiāo da Paulista, os chamados "edifícios inteligentes" proliferaram-se, e assim, novos bairros de negócios foram se formando nos arredores da Av. Faria Lima, Juscelino Kubitschek e Berrini, englobando os bairros do Itaim-Bibi, Vila Olímpia e Vila Funchal. E com base nessa configuraçáo socioespacial apresentada, que o setor hoteleiro passou a se expandir rapidamente nos últimos anos do século xx e primeira década do século XXI. $\mathrm{O}$ meio pelo qual esta expansão rápida aconteceu foi encontrado em um novo formato de empreendimento voltado para o setor de hospedagem: os flats ou apart-hotéis. 
As diferenças entre flat e hotel estão no seu posicionamento de mercado, na estrutura administrativa e na configuração arquitetônica interna. $O$ primeiro se caracteriza por ser um empreendimento imobiliário de caráter residencial, ou seja, é considerado residência e não unidade habitacional para uso diário restritamente, como são os hotéis. É administrado de forma conjunta a partir de um condomínio gerenciado por uma empresa que náo necessariamente pertence ao ramo hoteleiro, o que o difere dos hotéis que são administrados por uma empresa do setor hoteleiro e que trabalha especificamente com tal ramo; os flats possuem subdivisão interna diferenciada, podendo ter até dois quartos além de sala de estar e banheiro, pois são voltados para a hospedagem do tipo long stay ${ }^{3}$, já os hotéis são unidades habitacionais simples, na maior parte das vezes sem subdivisão interna além do cômodo onde se encontra a cama e o banheiro, sem infra-estrutura para longa permanência. Além disso, como flat é considerado condomínio residencial as taxas e impostos são diferenciadas das dos hotéis, já que eles não necessitam pagar iss e nem taxas de turismo, podendo tanto trabalhar com o hóspede que necessita de apenas uma noite de hospedagem como aquele que requer um, seis, doze ou mais meses de permanência na unidade habitacional.

Conforme os informativos setoriais do BNDEs de 2005, no que tange ao desenvolvimento da hotelaria nacional, o mercado de flats que deveria estar voltado para o uso de longas permanências nas cidades, foi sendo descaracterizado ao ser utilizado como meio de hospedagem normal e concorrendo com o segmento hoteleiro de forma desleal, já que é considerado como condomínio e não como empresa, colocando-se, portanto, de forma diferenciada no pagamento de taxas e tributos, além de gastos com pessoal e serviços públicos.

$\mathrm{Na}$ realidade, como o setor hoteleiro viu-se em estagnação na década de 1980, a alternativa flat foi utilizada para minimizar os baixos investimentos em novas inauguraçôes. Além disso, por ser um empreendimento especificamente do setor imobiliário, eles surgiram como possibilidade de investir em imóveis sem a necessidade do proprietário introduzi-lo no mercado tradicional de locaçóes. Ou seja, por meio do condomínio o imóvel adquirido por um proprietário individual e particular é administrado de forma conjunta e coletiva e os lucros advindos da consequente locação eventual ou long stay lhe é repassado.

O empreendimento do tipo flat, deste modo, se apresenta ao mercado imobiliário como nova alternativa para se investir no setor. Diferentemente do mercado tradicional de aluguéis ou compra e venda de apartamentos ou casas, o flat é uma maneira de adquirir imóveis sem que o proprietário se encarregue de administrá-lo sozinho, já que o condomínio o fará de forma a facilitar todos os trâmites administrativos contidos no uso do bem residencial patrimoniado do proprietário da unidade habitacional.

A discussão sobre os flats e a expansão do número de unidades hoteleiras com sua respectiva crise acontecida em um período inferior a dez anos é necessária, pois a crise

3 Longa permanência do hóspede na cidade sem que esse precise alugar um imóvel no mercado tradicional, ou seja, das imobiliárias com fiador, locatário etc. Os flats oferecem microondas, equipamentos de cozinha, serviços de arrumadeira e outros de forma mais completa do que nos hotéis. 
acontecida no setor de flats vai afetar diretamente na quantidade, localização e gestão dos novos hotéis de luxo em São Paulo, sobretudo no que tange ao papel destes hotéis como elementos que participam na atualidade, do processo de reproduçáo do espaço urbano por meio da reprodução do capital financeiro em união ao imobiliário.

Sob o ponto de vista do negócio imobiliário, o flat administrado na forma de um pool hoteleiro, transforma o apartamento adquirido individualmente pelo investidor, em um formato de maior rentabilidade, já que o introduz no mercado de locaçôes por meio da sazonalidade hoteleira. Assim, a categorização como meio de hospedagem com fins comerciais sendo utilizado como residência temporária, auxilia na expansão dos investimentos imobiliários, porque atrai mais investidores que buscam neste formato, aumentar os seus ganhos em curto prazo, mesmo imobilizando o capital.

Para o incorporador imobiliário, a pulverização dos investimentos no setor por meio da compra individual das unidades habitacionais dos flats, apresenta-se como nova possibilidade de expansão das entradas de capital para o setor. Ou seja, o mercado imobiliário incorpora novas formas e fontes de investimento e financiamento, ampliando para além daqueles vinculados a bancos públicos e privados de financiamento, fundos de pensáo ou mesmo capital privado empresarial, os modos como adquire dinheiro para construir.

Vale ressaltar que muitos empreendimentos hoteleiros, sejam flats ou hotéis, também foram construídos por meio dos fundos de investimentos imobiliários e por fundos de pensáo de inúmeras grandes empresas estatais e privadas do país, para citar apenas algumas práticas existentes no mercado imobiliário e que permitiram a expansão do setor hoteleiro.

Os fundos de investimentos imobiliários são um mecanismo financeiro criado pelo mercado imobiliário em diálogo com o mercado financeiro que permite aos pequenos, médios e grandes investidores tornarem-se sócios de empreendimentos imobiliários no mercado de capitais e açôes. Conforme aponta Fix (2007, p. 65) "a vantagem, do ponto de vista do setor imobiliário, é que esses fundos seriam uma nova forma de reunir recursos para investimentos, sem fragmentar a propriedade do imóvel". Ou seja, a partir da constituição de um fundo de investimentos imobiliários, os investidores compram cotas que representam uma fração do capital total em transação no empreendimento imobiliário. É uma forma de transferir dinheiro aplicado pelo capital individual de investidores a um fundo coletivo, juridicamente melhor estabelecido no mercado, favorecendo a expansão do capital disponível a ser utilizado para a construção de novos empreendimentos.

No caso dos fundos de pensão, estes se caracterizam como detentores de grande quantidade de capital disponível para investimento já que são abastecidos mensalmente pelas contribuiçóes dos pensionistas. Entre os mais atuantes no cenário imobiliário paulistano encontram-se os fundos de pensão dos funcionários da Caixa Econômica Federal (funcef), do Banco do Brasil (previ), da Vale do Rio Doce (valia) e da Petrobrás (PETros), além de outros.

No setor hoteleiro a participaçáo dos fundos de pensão foi determinante para a expansão da rede nacional de hotéis Blue Tree Towers. A funcef é a detentora de todos os imóveis da rede Blue Tree na cidade de São Paulo, por exemplo. A soma de 
todos os quartos e apartamentos desta rede em São Paulo ultrapassa 4.000, ou seja, o papel de financiador do Blue Tree pelo FUNCEF foi determinante para a expansão geral no número de apartamentos na cidade como um todo, o que revela o impacto dos fundos de pensão na estruturação e expansão do setor.

\section{A crise e a retomada do crescimento da hotelaria paulistana}

O que estamos chamando de crise da hotelaria foi o que se vislumbrou com a queda rápida e substancial no valor médio das diárias, levando São Paulo a ser considerada internacionalmente, como a cidade que continha alguns dos hotéis de luxo com os serviços mais baratos entre todas as cidades de negócios do mundo. Além do preço da diária, a taxa de ocupaçáo despencou devido ao excesso de oferta. Muitos hotéis de padrão intermediário passaram a concorrer diretamente com os flats. No entanto, como já ressaltamos, os flats possuem custos operacionais mais baixos que os hotéis, o que levou a muitos hotéis a fecharem suas portas. No caso dos hotéis de luxo, alguns no período de sua inauguraçáo, tiveram os seus primeiros meses de funcionamento com taxa média de $25 \%$, o que é considerado impossível para um empreendimento manter-se aberto e com rentabilidade.

A crise na hotelaria paulistana somente aconteceu em uma porção da metrópole. A concentração das unidades revelou que somente a região sudoeste continha as condiçôes para o funcionamento dos novos empreendimentos. Assim, foi somente nesta regiáo que aconteceu o que estamos chamando de crise. Nas demais áreas, por exemplo, na zona leste ou norte, não houve crise de super-oferta ou problemas na queda do valor da diária, porque não eram regióes que passaram pela especulação imobiliária vinculada ao setor hoteleiro, ou seja, não abriram hotéis ou flats em número considerável nestas regiôes. Elas não se apresentavam como localizaçôes passíveis de serem inseridas no movimento de consumo do espaço realizado pelos incorporadores imobiliários que concentraram suas atividades na região sudoeste de São Paulo. Assim, não tiveram problemas de superoferta porque nem oferta elas ofereciam.

A análise da crise da hotelaria de São Paulo, não pode ser desvinculada da crise de superoferta também contida no mercado de escritórios disponíveis para locação na região sudoeste de São Paulo. Com o desenvolvimento do setor imobiliário através da busca de capitais em agentes públicos e privados de financiamentos, aliados a demanda internacional por escritórios e edifícios empresariais em São Paulo, uma série de arranjos entre os sujeitos envolvidos no processo de produção do espaço urbano entraram em funcionamento para permitir efetivamente, a produção de uma nova área da cidade.

Deste modo, a necessidade de expansão por meio dos flats e dos novos hotéis mostrava-se adaptada ao discurso do desenvolvimento paulistano e seu lugar no campo das cidades mundiais. Logo, o papel do incorporador e promotor imobiliário ganhou destaque para a busca efetiva de terrenos em condiçóes de se transformarem em edifícios para a indústria hoteleira, que passou a significar um meio de valorização do capital a partir da taxa de retorno que a locação e uso da unidade habitacional traria para o investidor de maneira mais rápida do que se ele aplicasse em outra opção no quadro de oportunidades da indústria imobiliária, por exemplo o de escritórios. 
Aliado a este fato da escolha da localização do empreendimento, o incorporador, em contato direto com a administradora do edifício hoteleiro a ser construído, passou a trabalhar na organização do pool de investidores individuais que colocariam, em conjunto, grande parte do capital necessário para a construção do prédio ou, na maior parte das vezes, como o principal investidor na forma de um agente coletivo formado por unidades individuais. Além deste papel, as empresas de marketing em contato com consultores imobiliários independentes e as imobiliárias e gestoras de imóveis construíam o discurso que se tornou público por meio de matérias veiculadas pelos jornais, revistas e televisão, como sendo uma ótima opção de investimento de capital, a compra de unidades hoteleiras (apartamentos ou quartos) e flats. Ou seja, com um baixo capital inicial, o investidor individual conquistava um imóvel sem precisar colocá-lo no mercado tradicional de locação.

É a partir desta leitura que o mercado hoteleiro de São Paulo entra em uma crise de superoferta, pois incitou uma grande quantidade de investidores individuais que colocaram dinheiro no setor, mas que em um período curto de tempo, viram que o excesso de opçóes fez os lucros desta atitude de investir, caírem demasiadamente, deixando de ser uma opção rentável. Somente no período 1995-2002 foram mais de 40 prédios destinados ao mercado hoteleiro construídos em Sáo Paulo, o que na prática colocava a disposição mais de 15.000 quartos para hospedagem diariamente.

Do ponto de vista da geografia a crise da hotelaria paulistana revela um momento de crise que não está restrito ao setor de hospedagens apenas, mas é inerente ao sistema capitalista de produçáo. As crises no sistema revelam adaptaçóes e novas articulaçóes entre os sujeitos envolvidos no processo de produção do espaço. A cidade apresentava as condiçóes para ampliar o mercado de empreendimentos imobiliários voltados ao setor de hospedagens porque passava por um período de refuncionalizaçáo com a ampliação de seu eixo central de negócios para além da região da Avenida Paulista com a entrada maciça de novos investimentos em firmas e empresas que necessitavam de escritórios e edifícios para funcionar suas sedes administrativas, fruto de uma nova etapa de reprodução do capital, a qual colocava São Paulo, como uma cidade primaz para o desenvolvimento econômico brasileiro. É assim, que a consolidaçáo do eixo comercial-empresarial envolvendo a regiáo sudoeste da cidade acontece, com a produção efetiva do espaço urbano por meio dos investimentos diretos em imóveis corporativos e residenciais de médio e alto padrão, atendendo às novas exigências da atual fase do capitalismo contemporâneo que vinha se desenrolando.

A crise na hotelaria, assim, está inteiramente conectada às crises cíclicas encontradas no processo de reprodução das condiçôes do sistema capitalista de produção que cria mecanismos de autorregulação para poder continuar a se expandir. É após 2006 que o setor hoteleiro paulistano começou a se recuperar da crise da superoferta. Vários foram os empreendimentos que deixaram de funcionar como flats e passaram a ser utilizados apenas como residências. Deste modo, com a autorregulação do setor aliada as novas condiçóes que o mercado internacional apresentava a São Paulo, principalmente com a sua posição de destaque como principal metrópole latinoamericana no que tange à articulação da economia regional à global, foram sendo gestadas as condiçôes para a hotelaria se firmar como um setor lucrativo. Ou seja, 
aliada a autorregulação do setor, com o fechamento de unidades hoteleiras e a transformação dos flats em edifícios residenciais, São Paulo vive um momento de grande expansão na atração de novos investimentos de capital, o que vem atraindo viajantes de negócios que demandam, a cada ano, maior quantidade de noites de hospedagem. A consolidação do crescimento econômico brasileiro e seu protagonismo no cenário internacional, tendo Sáo Paulo como a principal porta de diálogo nas relaçóes comerciais e empresariais, auxiliaram o setor a sair da crise e a se recuperar.

Figura I | Mapa de localização dos hotéis de luxo em São Paulo em 2012

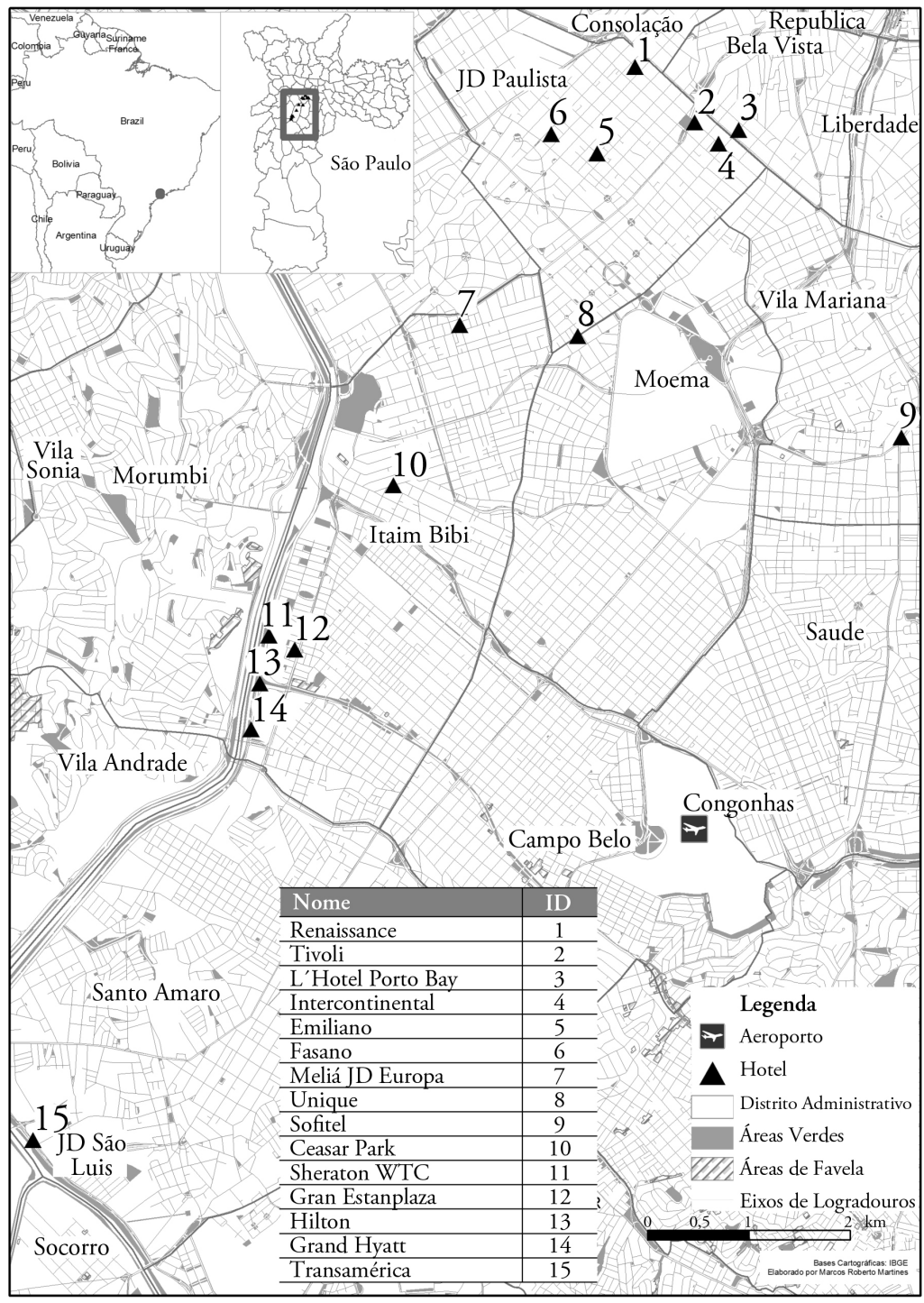

FONTE PESQUISA DIRETA 
O último relatório da АВıн (Associação Brasileira da Indústria Hoteleira) mostra que a cidade possui a maior rede hoteleira da América do Sul com 42.000 apartamentos e que em 2011 teve taxa de ocupação média de $70 \%$ e preço médio da diária de $\mathrm{R} \$ 215,00$. Em 2001, esta taxa era de $45 \%$ e a diária média de $\mathrm{R} \$ 85,00$. Considerando apenas os empreendimentos de luxo, São Paulo se destaca hoje, como uma das cidades mais caras do mundo. $\mathrm{O}$ valor da diária média entre os 13 empreendimentos de luxo é de US $\$ 315,00$ o que a coloca como a $10^{0}$ cidade mais cara do mundo para se hospedar quando se trata de hotéis de alto padrão, conforme relatório da IAHG (International Association Hospitality Group). A taxa de ocupação dos empreendimentos de luxo fechou 2011 na ordem de 79\%, ou seja, bem acima da média geral da cidade. Em algumas datas especiais como feriados ou períodos de importantes eventos na cidade, estes hotéis alcançam sua capacidade máxima de ocupação, mesmo trabalhando com valores altos.

A Figura 1 contém a localização dos hotéis de luxo em São Paulo e por esta, podemos visualizar sua concentração no eixo comercial-empresarial que se estende da Avenida Paulista até a Av. Eng Luis Carlos Berrini, envolvendo os distritos de Jardim Paulista, Itaim Bibi, Pinheiros, Moema e Morumbi. Nesses distritos também residem famílias com os maiores níveis de rendimentos médios da metrópole e onde concentram os principais serviços de lazer voltados para o consumo.

\section{Consideraçóes finais}

A análise da hotelaria paulistana nos últimos anos nos possibilita enxergar a dinâmica socioespecial do processo de reprodução do espaço da metrópole paulista. A hotelaria acompanhou a construção e consolidação das novas áreas de negócios da cidade ao longo da formação do eixo comercial-empresarial que se solidificou a partir de meados da década de 1990. Com a maior disponibilidade de terrenos para incorporaçáo, venda e locaçáo permitida pelo mercado imobiliário auxiliado pelos ganhos efetivos de capital no mercado financeiro e sua transferência para a construçáo civil, já que esta apresentava novas e melhores condiçóes para a reproduçáo ampliada do lucro naquele momento do final dos anos 1990, a hotelaria por meio dos flats expandiu-se rapidamente. No entanto, a expansão rápida não significou ganhos reais para os investidores, o que foi refletido pela crise da superoferta entre 2001 e 2003.

Os últimos dez anos, no entanto, têm mostrado a recuperação do setor hoteleiro com o aumento gradual da taxa de ocupação e do valor cobrado pelas diárias. Além disso, o mercado de hotéis de luxo tem permanecido sem novos investimentos desde 2004. Ou seja, faz aproximadamente oito anos que em São Paulo não se inaugura um hotel de luxo.

Com a ocorrência da Copa do Mundo de Futebol em 2014, a cidade espera receber muitos turistas que deveráo ser acomodados em seu parque hoteleiro. Conforme reportagens veiculadas pela imprensa televisiva, a cidade deve receber investimentos em hotéis de luxo com a abertura de três novos empreendimentos na regiāo dos Jardins, Vila Olímpia e Marginal Pinheiros. Ou seja, os novos hotéis se localizarão, necessariamente, na região na qual já estão em funcionamento os atuais 14 hotéis de luxo. 
Esse dado nos possibilita reforçar nossa hipótese de que a hotelaria, sobretudo a de alto padrão, se localiza nas melhores localizaçóes vinculadas ao desenvolvimento dos negócios corporativos e das atividades de lazer voltadas para os setores de maiores rendimentos da metrópole paulista. Em São Paulo a análise da hotelaria mostra que o sucesso do setor está vinculado com a consolidação de São Paulo enquanto plataforma do desenvolvimento econômico brasileiro e latino-americano, atraindo para seu interior, cada vez mais, visitantes e viajantes que buscam realizar transaçóes comerciais em sua área comercial-empresarial. A capacidade de desenvolver novas atividades que funcionem como serviços de apoio para este fluxo de pessoas que a cada ano aumenta, se vincula com o setor de lazer que cresce exponencialmente, principalmente com a oferta de novos empreendimentos nos setores de alimentação, exposiçôes de arte, casas de cultura, espetáculos, obras teatrais, musicais, bares, discotecas, lojas, shopping centers, etc.

\section{Referências bibliográficas}

Carlos, A.F.A. (2001). Espaço tempo na metrópole. São Paulo: Contexto.

Carlos, A.F.A. (2004a). O espaço urbano: novos escritos sobre a cidade. São Paulo: Contexto.

Carlos, A.F.A. (2004b). São Paulo: do capital industrial ao capital financeiro. Em A.F.A. Carlos \& A.U Oliveira (Orgs.), Geografias de São Paulo: a metrópole do século xxi (pp. 51-83). Sáo Paulo: Contexto.

Carlos, A.F.A. (2005). A reprodução da cidade como "negócio". Em A.F.A. Carlos \& C. Carreras, Urbanização e Mundialização (pp. 29-37). São Paulo: Contexto.

Carlos, A.F.A. \& Pintaudi, S.M. (1995). Espaço e indústria no Estado de São Paulo. Revista Brasileira de Geografia (Rio de Janeiro), 57(1), 5-23.

Chesnais, F. (1995). A mundialização do capital. São Paulo: Xamã.

Ferreira, J.S.W. (2003). São Paulo: o mito da cidade global. São Paulo. Sáo Paulo: Faculdade de Arquitetura e Urbanismo da Universidade de Sáo Paulo (fau/UsP). Tese (Doutorado em Arquitetura e Urbanismo) faU/UsP.

Fix, M. (2007). São Paulo: Cidade global: fundamentos financeiros de uma miragem. São Paulo: Boitempo.

Harvey, D. (1992). Condição pós moderna. Rio de Janeiro: Ed. Loyola.

Harvey, D. (2005). A produção capitalista do espaço. São Paulo: Annablume.

Lencioni, S. (1997). Mudanças na metrópole de São Paulo e transformações industriais. Revista do Departamento de Geografia (São Paulo: Faculdade de Filosofia, Letras e Ciências Humanas, Universidade de São Paulo-fFLch/usp), (12), 27-42.

Nobre, E.A.C. (1999). Reestruturaçấo econômica e território: expansão recente do terciário na marginal do Rio Pinheiros. Tese (Doutorado em Arquitetura e Urbanismo), fau/UsP.

Rolnik, R. (2001). São Paulo. São Paulo: Publifolha.

Silva, A.M.B. (2001). A contemporaneidade em São Paulo: produção de informaçōes e o novo uso do território brasileiro. Tese (Doutorado em Geografia), FFLCH/UsP. 
Silva, C.H.C. (2008). A reprodução do espaço urbano na perspectiva da hotelaria de alto padrão. Tese (Doutorado em Geografia). Rio Claro: Universidade Estatal Paulista/Instituto de Geociências e Ciências Exatas (Unesp/IGCE).

Silva, C.H.C. (2010a). O lugar dos hotéis de luxo na metrópole: negócios e turismo em São Paulo. Revista Percurso (Maringá), 01(02), 97-123. Disponível em http://www. periodicos.uem.br/ojs/index.php/Percurso/article/view/11661

Silva, C.H.C. (2010b). Uma leitura geográfica dos meios de hospedagem: O lugar da hotelaria na produção do espaço da Metrópole Paulista. Em S.E.C. Pitton \& F.D. Antonio Filho, Geografia plural: Única e múltipla (pp. 95-122). Rio Claro, Brasil: UnEsP/IGCE. Spolon, A.P.G. (2006). Chão de estrelas: Hotelaria e produção imobiliária em São Paulo, $1995-$ 2005. Dissertação (Mestrado em Arquitetura e Urbanismo), fau/usp, São Paulo.

Tourinho, A.O. (2005). Centro e centralidade: uma questão recente. Em A.F.A Carlos \& A. U. Oliveira (Orgs.), Geografias das metrópoles (pp. 277-300). São Paulo: Contexto. 